\title{
Schools in the making: \\ Mapping digital spaces of evidence
}

Mathias Decuypere(a*), Carlijne Ceulemans(b) \& Maarten Simons(a)

(a) Laboratory for Education and Society, University of Leuven, Leuven, Belgium

(b) Institute for Information and Education Sciences, University of Antwerp, Antwerp, Belgium

\begin{abstract}
In this article, the focus is on educational governing in the making. Drawing on conceptual underpinnings of socio-technical approaches, this implies an interest both on the way in which a sound knowledge base for policy measures is created, as on the distribution of that knowledge through publically available instruments. Governing by evidence only is possible when it relies on concrete instruments, such as feedback reports, publically consultable audits and examples of good practice. Since knowledge related practices increasingly make use of online tools, where knowledge is accessible for each and all, three websites are analyzed in a particular way to describe the making of evidence. First, considered as active devices, the websites are analyzed as essential components of the governing by evidence: by publishing specific data and information in a particular way, they come to constitute what comes to count as evidence and the way in which it comes to count. By addressing their visitors in a particular way, moreover, they constitute for whom it comes to count as evidence. As such, we argue, it becomes visible that digital spaces of evidence actually make schools real, and, at once, that there are different modes for schools to exist.
\end{abstract}

Keywords: Educational governing; Examples of good practice; Inspectorate, School feedback; Sociotechnical approaches

To cite this article: Mathias Decuypere, Carlijne Ceulemans \& Maarten Simons (2014) Schools in the making: mapping digital spaces of evidence, Journal of Education Policy, 29:5, 617-639, DOI: 10.1080/02680939.2013.865081

To link to this article: $h$ ttp://dx.doi.org/10.1080/02680939.2013.865081

*Corresponding author. Email: mathias.decuypere@ppw.kuleuven.be 


\section{Schools in the making \\ Mapping digital spaces of evidence}

\section{Introduction}

\section{Education policy and/in Belgium (Flanders)}

In Belgium (Flemish community), as in many other parts of the world, education policy measures are increasingly envisaged as measures that need to be founded on a sound knowledge base. Consequently, as promoted by the current Ministry of Education (e.g. Smet 2009; Flemish Parliament 2011; or, focusing on the former Ministry of Education as analyzed by Verckens, Simons, and Kelchtermans 2009), performance measures, standards and examples of good practice have become a common ground to talk about Flemish education. These measures, standards and examples are, however, not just collected in order to create a knowledge base for policy preparation and political decision making. Equally important is that the distribution of knowledge itself becomes part and parcel of Flanders' educational governing. That is, the field of education is being governed by the distribution of knowledge through instruments such as feedback reports, publically consultable audits and tales or images of good practices ( Delvaux \& Mangez 2008; Simons 2007).

In this article we want to contribute to the study of the governing of education through knowledge in general, and more specifically, to the way in which schools are governed through this knowledge. We will do this by focusing on two issues. A first focus is on publicly available instruments by which knowledge is portrayed as evidence (of a particular kind) in the governing of education. Focusing on the way such knowledge is portrayed implies a close look at the functioning of concrete practices in and through which data, information and knowledge on education become (publically) available as forms of evidence to be used by schools, policy makers and citizens. Specifically, attention is given to the particular kind of user implied in and constructed through these instruments. Second, we start from the assumption that these knowledge related practices of governing increasingly make use of online tools. By emerging online, evidence about education becomes accessible for each and all (every potential interested citizen might consult these websites). Equally, different sorts of data, information and knowledge about education appear 'side by side', at the same level and at a same distance to the user (in just a few mouse clicks, various sorts of evidence can be found). In line with the two points of departure, we selected three publically consultable websites to describe the making of evidence. In making this selection, we purposefully looked for differences in the sources of knowledge and for different actors partaking in its distribution. As such, we could articulate distinct types of 'governing by evidence' as these take place in Belgium (Flemish community) nowadays. First, a specific case of bottom-up generated knowledge (innovation projects by schools) that is initiated and facilitated by the Flemish government by means of providing examples of good practice (ond.vlaanderen.be/proeftuinen); second, knowledge supplied by the government itself and produced by the inspection through school audits (ond.vlaanderen.be/inspectie); and third, a school feedback system organized by (academic) research centers as incentive for school improvement (schoolfeedback.be). Although these three websites are unique to the Flemish case and linked up with the specific governing context, they resemble governing practices in other countries: the use of examples of good practice is an increasingly common practice in European policy spaces (see also Lawn 2006). This equally applies to governing through inspection and inspection reports (e.g. Grek 
2009; Grek and Ozga 2008) and governing through assessment data provided (e.g. Delvaux \& Mangez 2008).

\section{Websites as socio-technical devices}

Governing by evidence is only rendered possible if this governing relies on concrete instruments, such as, in the scope of this article, websites. Such instruments are no passive hatchways of information dispersal. Rather, they are active platforms that perform particular operations. The knowledge portrayed on a website, for instance, is transferred to interested users by means of communicative techniques (e.g. tabs, links etc.) in such a way as to be clear and appropriate for the user. Taking the agency of these websites seriously implies not to approach them as mere neutral tools, each solely acting as a digital hatchway of sorts of 'evidence' (for instance a report) and with a specific intent (for instance in view of allowing visitors to get informed). Rather, they are approached as active agencies or devices themselves whose very operations have to be analyzed on their own terms. The importance of investigating such partly digital assemblages as active devices has been recognized recently (Latour et al. 2012; Lascoumes and Le Gales 2007; Venturini 2012; Savage, Ruppert, and Law 2010). Considered as active devices, the websites are analyzed as essential components of the governing by knowledge: by publishing specific data and information in a particular way, they actually constitute what comes to count as knowledge and how, and, by addressing their visitors in a particular way, for whom it comes to count as knowledge. All three websites perform particular operations that elevate 'information' to the status of 'knowledge' on the one hand, but they also enact and stage this knowledge as authoritative point of departure for those visiting the website on the other hand. In respect to the latter, we argue to consider the agency of these websites in terms of the operations they perform towards the visitors who navigate these websites: how do these websites address their visitors and how do these sites, as active agents, not only enact some particular types of knowledge but, equally, some particular types of visitors? In sum, we approached these websites as socio-technical devices: technical in as far as they perform particular operations and enactments that make that schools become real (and that it is possible to speak truth about schools with a certain authority based on portrayed knowledge), social in as far as they constitute specific interactions that install a particular self-understanding of the person visiting the website that make that schools become real for certain people (and that it is possible to act upon schools based on this knowledge) (Callon, Méadel, and Rabeharisoa 2002; Decuypere, Simons, and Masschelein 2011). This closely resembles a Foucaultian framing of governing as the 'conduct of conduct', by focusing on for instance what it is that certain technologies and procedures make people do, and how this steering at once includes forms of subjectivation and objectivation (Foucault 1982, p.237) Hence, in approaching websites as socio-technical devices, we seek to integrate two approaches: a Latourian approach that requires to analyze concrete working mechanisms and operations of the device studied in order to describe the processes by which 'knowledge' is rendered real (e.g. Latour 2005) and a Foucaultian approach focusing on how these devices at once constitute the subjectivity of a concrete user (that is, which specific kind of user is implied and hence called into being) and objectify the entities that are presented (that is, which specific kind of school is called into being) (see also Rose, 1999). Informed by the combination of these two approaches, the operations analyzed in what follows are directed towards the agential effects of different assemblages and thereby urge to analyze how exactly these agential effects come into being. In order to trace these agential effects, a detailed and 
careful study of micro-operations is needed that unfolds how precisely each website acts as a device. We have divided these operations into five different sorts that also acted as the focal points of attention of our analyses. First of all, how is knowledge being portrayed on each website? This will be highlighted by focusing in the different sorts of inscriptions that are used on each website, i.e.: the process by which different aspects of reality are transformed into graphs, figures, or texts (cf. Latour 1987). Secondly, on which aspects are schools being made comparable? This point of attention is informed by the contention that in order for schools to be compared, schools first of all need to be objectified as entities of which it is possible to compare certain characteristics. Third, how is the inscribed information regarding these comparisons made meaningful as forms of valid knowledge, i.e., which processes make it possible to make sense of these inscriptions and objectificaton? Fourth, on the basis of which mechanism does this portrayed knowledge gain legitimacy? That is to say, which kind of authority is installed precisely in and through these inscriptions (cf. Latour 1987)? Fifth, which types of activities is made possible by all of this, that is to say, which kind of user is called into being by means of all these operations.

In line with this combined approach, the following analysis attempts to map the assemblages of these three different websites from the viewpoint of its visitors or users. In so doing, we address a double research interest: First, how are the visitors of each website staged by the operations it performs as a device and how do schools become real for these visitors? Second, are these visitors staged in a similar way on all three websites, or do their operations differ? All this required a specific methodological approach: instead of approaching each website as a unidirectional process in which an unspecified 'maker' designs this website that subsequently provides its information to the visitor, each website was analyzed as a device performing particular actions in and on itself as well. Approaching websites likewise implies to focus on the different actors that assisted in the coming into being of this website (e.g. Latour 2005; Law 2009; Nimmo 2011). One could, for instance, focus on the graphic designer of the website; on the content producers that envisaged the different chunks of information to be put online; on the servers that stabilize each website as a to-be-visited entity; on the users of each website that are able to click on different tabs; etc. In this article, we are going to focus on this latter aspect by exemplifying how each website, as an active actor, performs particular operations which stage information and visitors in a particular way. In this sense, and in line with Davies (2008), the applied methodology is an autoethnographical approach. By upholding an autoethnographical approach, we (as researchers) positioned ourselves as potential visitors of each website and sought to make explicit through our use the various ways in which potential visitors of each website are addressed, and how and when information turns into knowledge (for us) and who schools are portrayed (to us). To give an account of these stagings and operations, an experimental kind of writing was required(Collins 2010) This experimental writing consisted in trying to give an 'adequate account' (Latour 2005) in terms of descriptions of what each website does and makes its visitors do (and understand themselves) on each particular subsection (mostly in the forms of different tabs the visitor can click upon). In a conclusive section, the three different analyses of these three websites will be compared and common and differing patterns in social and technical operations will be highlighted with a focus on spaces that correlate with each website. Finally, some critical remarks are formulated on the impacts of these digital spaces of evidence.

\section{A socio-technical analysis of three websites}

Testing grounds 
The legislative period of the former Flemish Minister of Education Frank Vandenbroucke gave birth to the website www.ond.vlaanderen.be/proeftuinen. The "proeftuinen" were an initiative on behalf of the Minister that sought to give bottom-up educational innovation anchoring in policy. "Proeftuin" is a Dutch term that is not easily translated: "proef" is deviated from the verb "proeven", which might equally mean "to taste" and "to try out"; "tuin" can be translated as "garden". The English term closest to "proeftuin" seems to be "testing ground" (from now on TG): a place where one can experiment and try things out.

The TG's homepage is entitled "Testing grounds: room for educational innovation" and accompanied by a logo which includes the motto "TESTING GROUNDS --- INNOVATION":

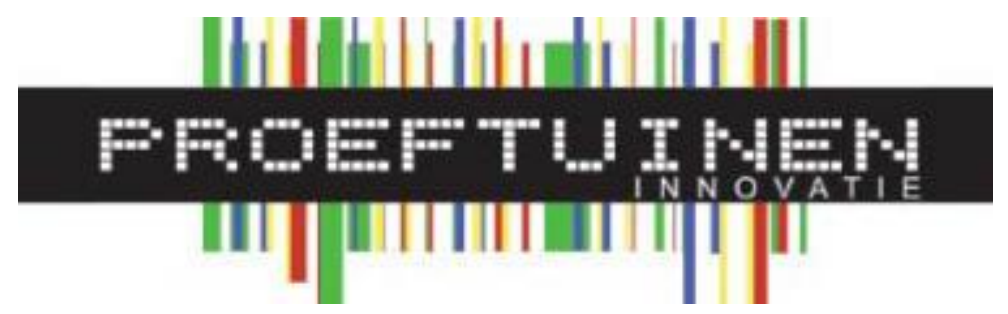

Figure 1. The testing grounds' logo

Under the homepage's logo, a short paragraph provides some information regarding the amount of TGs and the dates on which they were operational. Also given is a short overview of what is available under four different tabs of the website: different subjects and sorts of information. These tabs constitute the assemblage of the website, yet each separate tab performs different operations that both stage information-as-evidence and address visitors in a particular way.

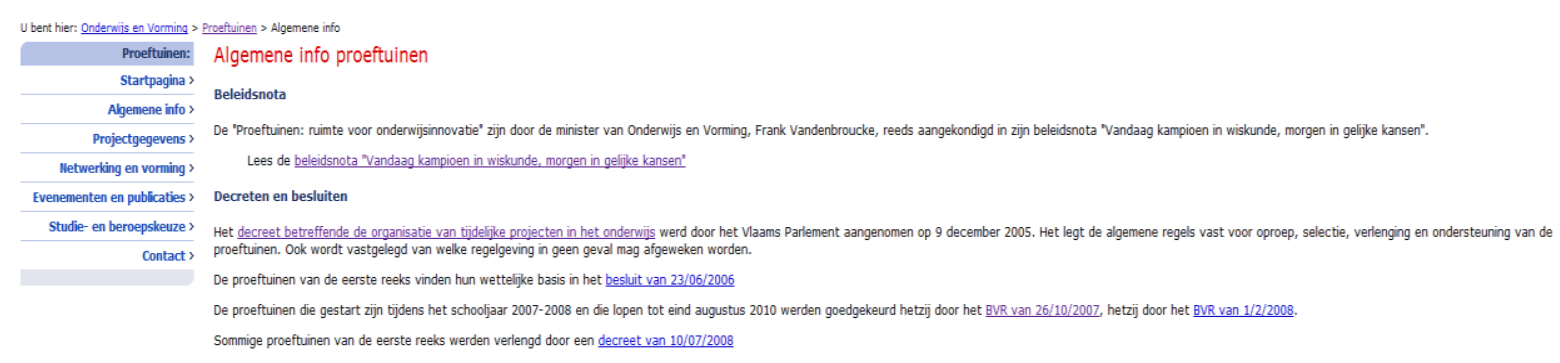

Figure 2. Hyperlinks to the Minister's Memorandum, decrees, and resolutions

The first tab "General information" is divided into four different sections. These two sections link with different actors in the Flemish policy field: with the Minister's memorandum in which he announces and frames TGs as policy method and with five different decrees and resolutions (see Figure 2). By linking with these different actors (policy documents), the website makes its visitors assured and confident that the idea of TGs in education has a sound general anchoring in policy and was specifically approved by the Minister. It is not even necessary to read these texts in order to be assured or confident: the mere fact that a surfer can see that they are available - that they are stored online - and that you can read them suffices.

A third paragraph deals with the "Evaluation of the first series of testing grounds". As is stated in this section, TGs are controlled by and under the surveillance of the Flemish inspectorate, and a first series of them has been inspected: 
The inspectorate believes that the testing grounds deployed sound and meaningful projects (...) and that in a lot of testing grounds, schools have been changed in a positive way by means of the innovations deployed. Yet, it is impossible to draw conclusions regarding generalization due to the diversity of the projects and sparse application of allowed deviations. (...) You can read the complete report here. (Our translation)

"Here" is pointing to a hyperlink that actually leads elsewhere, that is to say, to a document of 56 pages constructed by the inspectorate in order to report on its evaluation. Again, the website operates as a device shaping confidence: by referring to an authoritative actor as the inspectorate and the mere presence of a bulky document that you can read/consult, the website makes you inclined to trust the conclusion that schools change in a positive way by means of innovations deployed in TGs.

After being assured that TGs generate positive effects, in the fourth section the visitor is provided the opportunity to take a look at ten case studies which are at the same time designated as ten stories in which "each school in Flanders will surely recognize itself". By means of such phraseology, the website convinces its visitors that it is evident that these particular cases are recognizable for everyone involved in education. Furthermore, the case studies are presented as stories: narrations containing very concrete examples about very particular schools.

This particularity is a recurrent theme that is also manifest on the second tab of the website "Project data". In this section of the website, more information is given regarding each specific TG: listed here are the addresses of the different TGs, the different TGs categorized along themes and a brochure containing 42 examples of practice(s). The section "Contact info" links to a spreadsheet in which the visitor can retrieve detailed information about each TG: address, name of the person to contact, email, telephone number, etc. By means of the provision of its physical location and contact details, each TG is staged as a highly visible entity. In other words, the website operates as an agent by which not only results (i.e., the particular stories) are highly visible and consultable for each and all, but also includes every possible means to contact a particular TG and see where the above-mentioned stories are made and fabricated. 


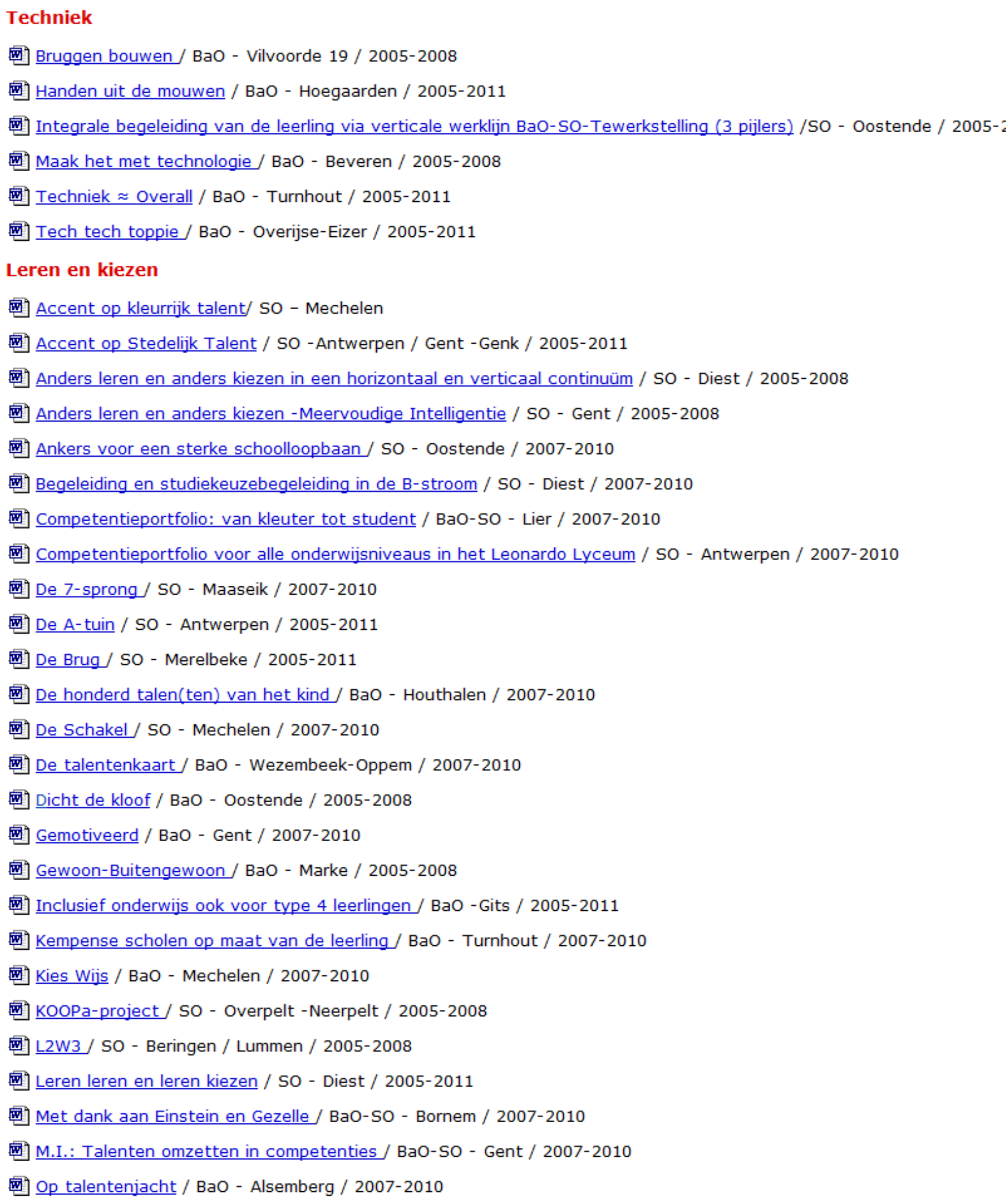

Figure 3. Categorization of testing grounds along different themes

In the second section of the second tab, the different TGs are ordered into different themes. The categorization of the TGs along themes links to a list of documents, one for each TG. In Figure 3 for instance, the themes 'Technics' and 'Learning and choosing' are shown. As this Figure illustrates, there is no further information regarding the separate projects: the only thing displayed on this website is a list of documents. Each document is approximately one page long and composed according to one format (out of two available ones), summarizing the particular TG-project and most of the time illustrated with a picture. In one and the same move, and by means of these formats, the website operates as a device, staging schools in two different ways. On the one hand, each school 
obtains room in order to display its particularity and specificity (which one can fill out in the format) and is at the same time made equivalent (they all have to fit in the format and are all included in the same list) on the other. Why a certain school made use of which particular format is not clear.

\begin{tabular}{cc}
\hline FORMAT ONE & FORMAT TWO \\
\hline Participating institution(s) & What? \\
Contact person & How? \\
Contact data & What do we learn from this? \\
$\begin{array}{c}\text { Keywords or core themes around } \\
\text { which the TG story is built }\end{array}$ & Who? \\
\hline
\end{tabular}

Table 1. Two different formats staging schools in particular ways

The first format again stages the core of TGs as being particular stories (cf. tab 1) - not as facts obtained by means of rigorous scientific conduct for instance. This differs from the second format, where the website does not confront its visitors with a story to read, but with documents that partly address these very visitors: What do we learn from this? The website thus addresses its visitors here as part of some kind of collective; a collective that is able to innovate and learn from each other's innovations.

"Networking and formation", the third tab of the website, continues to enact this collective. Its first sentences state:

Testing grounds do not stand alone. They themselves are owner of their project and hence responsible for its progression, yet the decree also provides support, networking and formation.

In other words, support, networking and formation are equally part of the collective circling around TGs: the website raises awareness that TGs have the opportunity to make good use of these initiatives developed and inaugurated especially for them and their particular needs. Besides nonhuman actors such as for instance the website, the physical TGs and the decree, another part of the TG-collective shaped on/by this website is constituted by means of people who were explicitly hired in order to support the TGs and by the people working in the physical TGs themselves. In the section "Network days" for instance, it is stated that these forums welcome "all people in education". Again, this shapes some sort of collective sentiment ("we, people/humans involved in education") and this operation is furthermore supported by specific language use: a rather non-formal utterance not easily associated with the conventional way in which governments communicate about their policy measures. Such utterances are present elsewhere on this tab as well, for instance in the usage of derivations of the word 'proeftuin', e.g. 'proeftuinier' and 'proeftuinen'. Recalling that the Dutch word 'tuin' is translated as 'garden', in English language the noun 'proeftuinier' would amount to 'testing gardener' and the verb 'proeftuinen' to 'testing gardening', such as in the following example: 


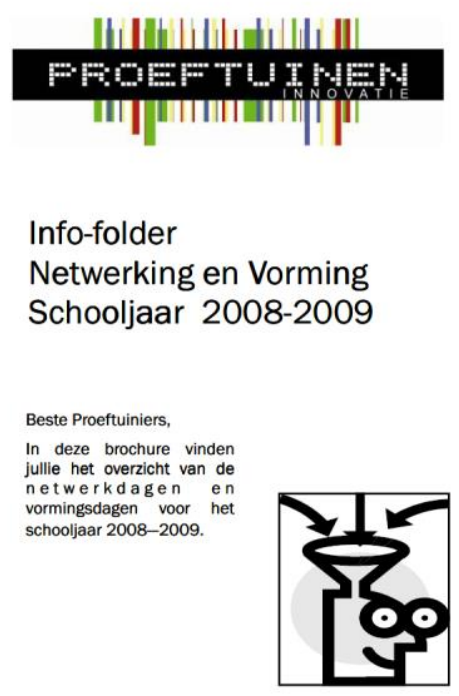

Figure 4. The first page of an information folder regarding networking and formation opportunities in the school year 2008-2009

The website, by staging its visitors as gardeners, then not only addresses these visitors in terms of a category (gardeners) but also addresses them as doers (who garden): whoever the actual users might be, as visitors of this website they are staged as actively engaged and participating in networking and formation days; as visitors who are willing to innovate (cf. Fig 1 ) and to do this in an active manner. Thus, the website conveys its visitors the message that you have to do things, that you have to try (to innovate). What is equally staged, however, is the message that visitors are never alone, since each visitor is addressed as and considered to be a gardener, and hence that each and all can innovate and learn from each and all - everyone is an example for everyone else.

The fourth tab "Events and publications" continues to build upon presentations that were formerly given. This tab mainly consists of links to video fragments about the concrete practices of some TGs, slides of presentations and speeches given by authoritative figures (the Minister, a professor, and an "expert in creativity and innovation"). Again the double dynamic of recognition and authority is performed here (see higher). This holds only partially for the fifth tab "Choice of studies and profession", on which links are given that might assist TGs in letting their pupils choose the right studies and/or profession. These links vary from governmental institutions to private initiatives that might be useful in this respect. On this tab, the website thus acts as some kind of hatchway between TGs and other organizations. Stated otherwise: the websites assembles a particular list of initiatives that frames the visitor at once as visitor-in-need-of-information.

In sum, the website performs particular operations that enact particular forms of evidence into being. 'Evidence' on this website often takes up the form of narrations (stories) that gain relevance because of their being recognizable and because they act as examples of fruitful innovation. Backed up by decrees and experts, the evidence that is portrayed on this website calls a collective into being, a collective consisting of active doers ('gardeners' as 'people in education') who all (want to) innovate and who are, because of that very reason, never alone. Fabricated as unique stories and narrations that are nevertheless fitting into the same formats, the same theoretical frameworks and 
the same space of experience and recognition, the website-as-assemblage performs TGs as highly unique and contextualized givens but equally as a collective sharing particular characteristics.

\section{Audit reports}

The Flemish inspectorate is responsible for the control of educational quality in schools in Flanders. In order to control this quality, the inspectorate organizes school audits that result in so-called audit reports. A website makes these audit reports available. The homepage of the website 'audit reports' (see Figure 5) includes a link to make selections in view of consulting the audit report of a particular school, but also includes several tabs with further information, entitled as follows: "What is an audit?, What is an auditing report?, What is a follow-up report?, What is a report on habitability, safety and hygiene?, Concept, Public questions, Links, Contact."

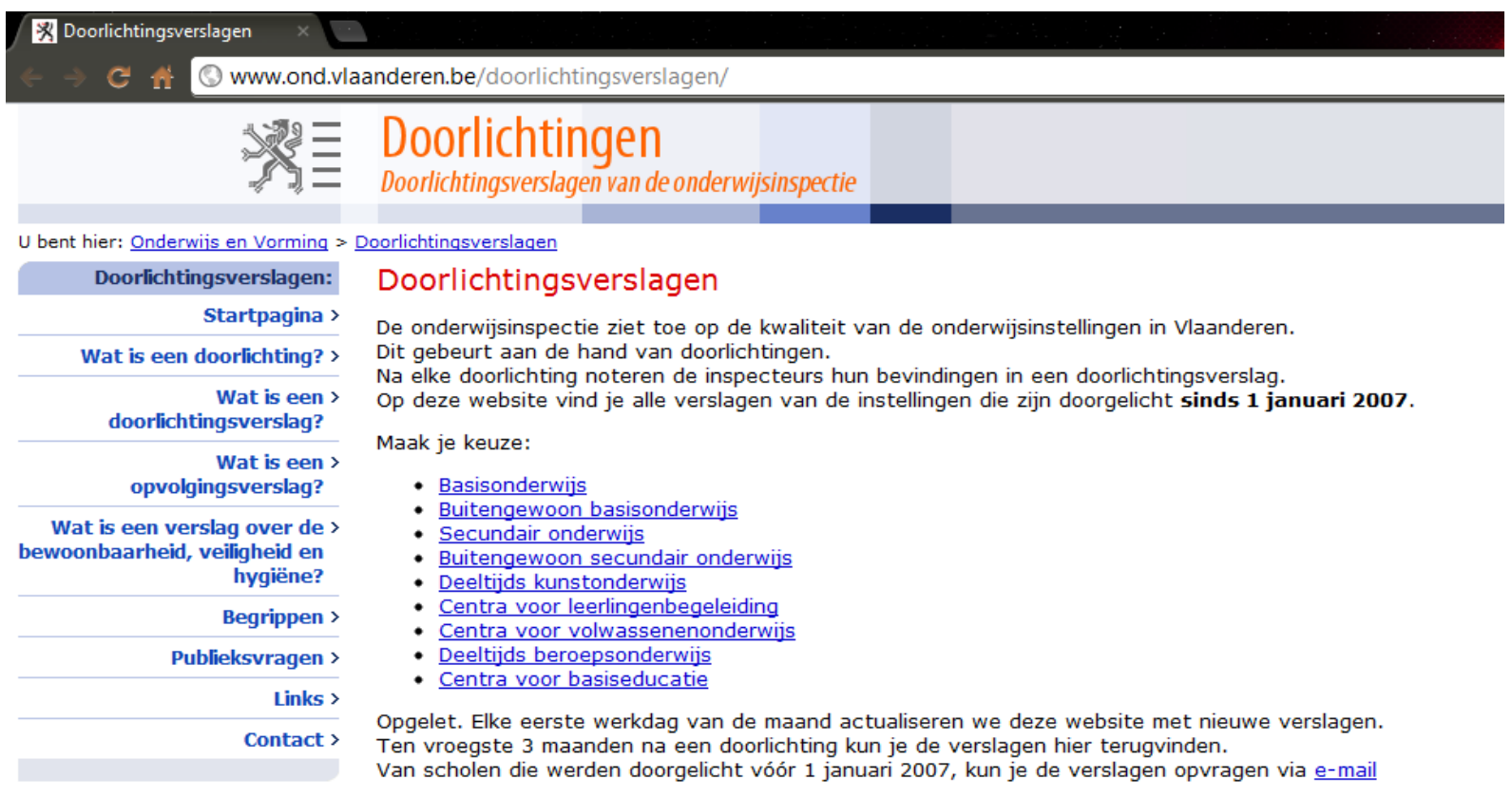

Figure 5. Homepage of website with audit reports of the Flemish Inspectorate

\section{Acts of contextualization}

The audit report for each school is available as a link to a pdf-file. These reports are written by a team of inspectors as part of an audit process and present a qualitative evaluation and formal statement on advise. As the website explicitly mentions, the reports are "in principle" intended for the Flemish government "in order to decide on the recognition and financing of the schools". Furthermore, a school can use the report to take "the further development of quality education in their own hands and adjust where needed". Finally, the websites states that "for parents the report can support the school choice for their children". Hence, it is suggested that an audit report makes three actions possible: decisions on recognition/financing (staging the government as ultimate decision-taker), quality assurance activities (staging schools as responsible agents in developing quality education) 
and school choice (staging parents as choosers to be informed). However, since these reports are first available to the government and to schools, before being available online, the website is mainly aimed at making the reports accessible to external visitors, and probably parents - although there is no specific mentioning of a defined target group. Both the explanation - "in principle" intended for government - and the format - a downloadable pdf with a formal report first to be discussed by the school staff - stage the visitors of the website as actors who are granted the opportunity to consult an internal document. These operations mark a distinction between internal users (inspectorate, government, and the audited school) and external users of the audit report. For external users, the website includes several operations that explicitly create context of a private and personal use - or consulting -for the audit reports.

First, the tabs on the homepage present factual information about the audits conducted by the inspectorate and about the resulting audit reports. The website clarifies that the inspection organizes school audits in order to assess whether schools realize their societal mission, that is, whether they "pursue development goals" and "meet the minimal attainment targets as set by the Flemish government". The audit reports are thus included in a legal context, staging the inspectorate as an agency with a specific mandate: to conduct audits in view of producing evidence on the quality of schools and to advise the government in view of recognition and funding.

Second, the audit process is summarized by mentioning three main phases: "pre-examination" (based on data centrally available and a one-day school visit in order to decide upon the audit focus), "the audit examination" (school visit in order to verify the estimated strengths and weaknesses), and "audit report" (of the findings, with a concrete advice to the Flemish government). At this point, the audit report is getting framed as part of a formal procedure exterior to the interest of the visitors of the website. This act of contextualization in terms of formal procedures is further specified when clarifying that the inspectorate uses a "CIPO-frame", that is, documenting, evaluating and reporting on "context, input, process and output indicators". The audit report is hence presented as part of a formal procedure of evaluation that draws on a standardized frame applied to each school.

Third, the website stresses the main objective of the audit process: advice. The three kinds of advices are explained ("favorable, restricted favorable, unfavorable"). By this, a legal, advisory context is added to the audit report: the audit report is specified as a type of advisory communication between the inspectorate and government (Minister of education), and disconnects the role of the inspectorate (which performs audits in view of advice) from the role of the government (which is the final decision-taker).

The tab "What is an audit report?" includes a further operation of contextualization under the title "How do you read an audit report?". The visitor is asked to read the report as a whole and thus without making a selection of specific parts ("for during an audit, the school is also approached as a whole") and to take into account that the report is 'temporally bound' ("each school is a living and learning organization for which quality development is a continuous process"). These comments operate as creating a specific reading context, that is, these comments function as actions to make these reports 'readable' and hence position these reports again as internal documents that, for external users, do not speak for themselves without additional guidance of use. 


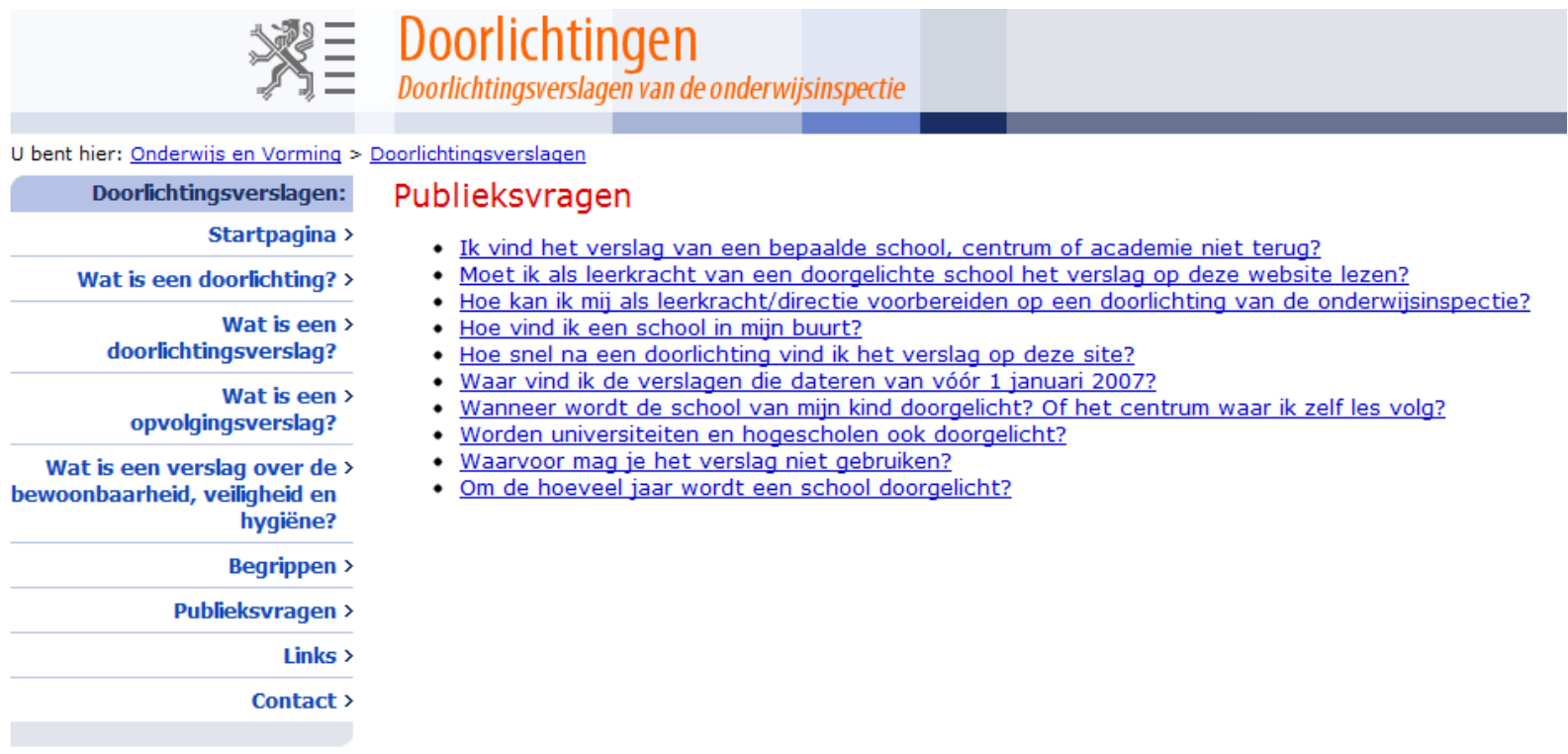

Figure 6. Webpage with "public questions"

Finally, the tab "Public questions" includes a list with questions that directly address the user of the audit reports (see Figure 6). Some of these questions are general, in the sense that the user is not specified: "How soon after an audit can I find the audit report on this website?" Based on the other questions, two profiles of users can be distinguished: parents ("When is the school of my child being audited?") and teachers/school leaders ("Do I, as a teacher of an audited school, have to read the audit report on this website?"). These questions reinforce the operations of contextualization discussed earlier through profiling and differentiating possible internal users (teachers, school leaders) and external users (parents).

In sum, as a socio-technical device the website performs several acts that on the one hand frame the audit reports as documents that do not speak for themselves (outside the formalized and standardized procedures of quality control) and on the other hand create a context of usage in order for the audit reports to make sense - that is, to become particular evidence - for these external users.

The personalization of consultation

The homepage of the website mentions "make your choice" followed by links that list different educational levels. At this point, the website stages the user as someone making a personal choice (that is, neither related to position nor anonymous). Personal choices are first of all oriented to educational level. 


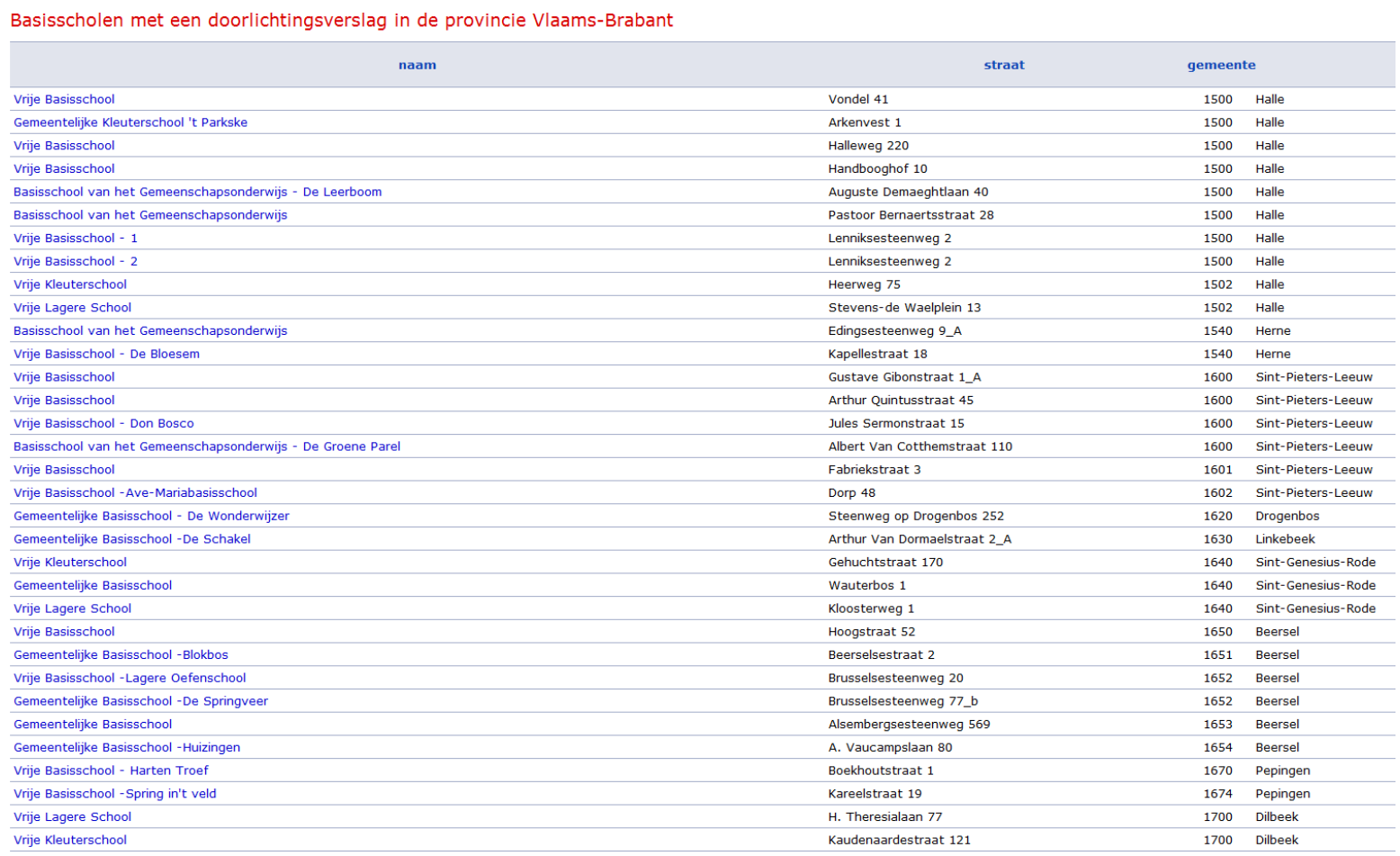

Figure 7. List (partial) of schools with audit report in the province Vlaams-Brabant

After selecting the desired educational level and province, a webpage opens with a list containing the names of the requested schools in the first column, the street in the second column and the postal code with municipality in the third column (see Figure 7). The list of schools is ordered by postal code of the municipality where the school is located. This ordering transforms the choice process into a search process with at least two different search profiles of visitors: those who want to consult the audit report of a school they have already selected, and those who want to explore possible schools in their region. In the search process, the agenda of the visitors of the website however bumps onto the agenda of the inspectorate: the lists (with schools in a particular region) are not exhaustive. Schools audited before 2007 are not listed (but can be delivered on demand), neither are the reports of schools who appeal against the inspectorate's audit and advice. For the visitor who is searching for a particular school, the result is a possible confusing situation for there is no (immediately available) information about the specific moment on which a school has been audited. Either she has to return to the start page in order to request a hardcopy of the audit report by email, or her school of choice is audited, but she has to 'wait' for the result of the appeal. Also for the visitor exploring different schools within a particular municipality, the search strategy confronts limitations: the list is not exhaustive, for only those schools audited after 2007 (and those who are not in appeal) are listed. These limitations reinforce the staging of the visitors as having a personal interest that is different from the agenda of the inspectorate. In other words, the website foremost gives external users discrete access to available audit reports, and does not straightforwardly enable school selection or school choice based on public reports.

The choice and search process ends by selecting a particular school. Each school name includes a hyperlink: for some schools it immediately leads to a downloadable pdf, for other schools it leads to a webpage with specific data of the school (name, address) and a hyperlink to an available audit report (for some it is only one, for others there is a choice to be made depending on the school year the audit took place). Having to download the audit report as a pdf - and for instance not a specific, 
new website for each school/report - once again stages the visitor as an external user of a document that is part of a formal procedure with the school, the inspection team and the government (Minister of education) as key players. The first sentence of the audit report - "This report is the result of the audit of your institution..." - includes an explicit act of externalization towards someone who consults the report. Although not all reports use exactly the same phrasing and introductory page, the audit report appears foremost as a communication between the inspectorate and the school (and government - given the advice formulated at the end of audit report). The externalization however at once includes a juridical binding, for its states explicitly that the report cannot be used for aims of publicity. As a consequence, downloading the document comes down to transferring the document from an internal sphere (inspectorate, school, government) to the external world (that of the interested, but external user), and acts are performed in order to constitute the external world as a (new) internal sphere by guiding personal usage. The website thus forces the visitors to make private and personal use of the reports.

Furthermore, as soon as one engages in reading the actual quality evaluation, the materiality of the audit report authorizes the inspectorate. One is immediately confronted with technical and administrative information, official references to the inspectorate's audit procedure and the standardized (CIPO-)frame, and this writing endows the inspectorate with authority (and not the other way around, which would be that the inspectorate grants authority to the report). Similarly, the report grants each specific school a particularity. This particularization is the result of the standard CIPO-framework that is at once applied to each school (however including a specific focus for each audit) and takes into account the unique features and context of each school. Here, the inspectorate is staged as an agency that makes a professional judgment about (and not a measurement of, as in the case of school feedback) the quality of a particular school. The standardized frame grants authority to the inspectorate's judgment, and this in turn gives authority to the quality evaluation in the report, that is, it makes the report speak with some authority about the quality of the particular school. The integrated presentation of 'professional judgment standardized frame -particular school' also implies that for external users, audit reports do not have to be compared in order to make sense. This finally means that the used criteria of 'valuation' are embodied in the value judgments of the inspectorate, hence not publicly available, which, in turn, reinforces the profiling of the inspectorate in terms of professional authority and autonomy.

In sum, the website includes several socio-technical operations that create a discrete user context and address the visitor as someone who consults a formal document. As a consequence, the website is not about organizing and enabling the actual school choice of parents itself, but about enabling the discrete consultation of a school's report as part of a personal choice process. In other words: as a device, the website constitutes the audit reports as evidence and makes the evidence public, but at the same time performs actions that atomize 'the public' as personal and discrete consulters of a report containing evidence that installs the professional authority of the inspectorate.

\section{School Feedback}

The "School Feedback Project" was an interdisciplinary research and development project, which ran from 2006 to 2010. Three Flemish universities collaborated in this project, that was funded by the Flemish Agency for Innovation through Science and Technology. "Each school its own mirror" is the motto advocated by the school feedback project, as displayed in the project's logo (see Figure 8). 


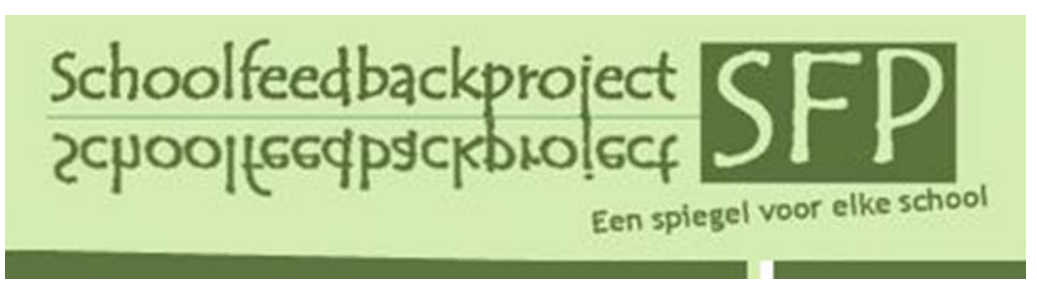

Figure 8. "Each School Its Own Mirror": The school feedback logo

Up to today, the project is continued by the Centre for School Feedback which operates through the website www.schoolfeedback.be. On the website's opening page, the visitor is welcomed by two entries to navigate through the website: "About school feedback" and "For those who are yet registered or wish to register: directly to our Schools Portal" (see Figure 9). Clicking the latter hyperlink leads to a login-page opening in a new screen, outside of the actual website. From here, only (teachers from) schools registered to the School Feedback System get access. Thus, similar to distinctions made by/on the audit reports-website, this website includes operations that distinguish between actual and potential users, and more specifically, actual and potential clients. Internal users (schools, teachers, researchers) have privatized access to confidential information, whereas external visitors are staged primarily as possible future 'clients' of the School feedback system. Thus, the website stages the information it provides at the same as privatized as well as commercialized. In the middle of the page, displayed in red, available tests for primary and secondary schools (in Dutch and Mathematics) are being advertised at discounted rates "if purchased before June 2015". Thus, the website recommends something to the visitor, aiming to convince him or her of its necessity to be used within a certain amount of time.

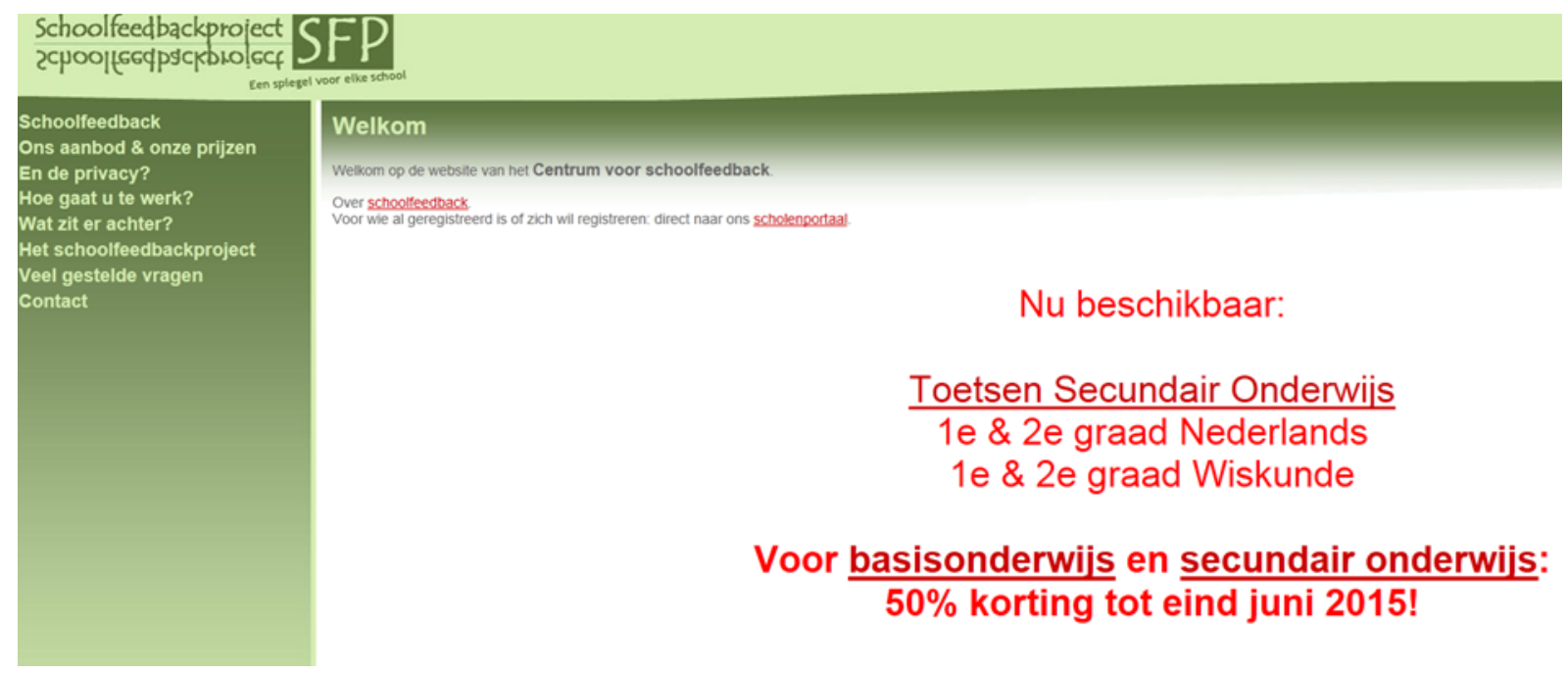

Figure 9. The school feedback website's opening page

The vertical toolbar consists of eight tabs, the first of which leads to the same page one encounters when clicking the "About school feedback"-button. Here, the Centre of School Feedback is introduced to the visitor, together with its main aim and a list of questions serving as tabs to navigate through the website: "What's inside school feedback?, Why school feedback?, When school feedback?, Who are we?, and What's new?" Following these tabs, the visitor is informed about the way in which school feedback is construed, what it is to be used for, and by whom it is provided. In so 
doing, the visitor - in particular, the website mentions schools, education and training institutions and educational researchers - gains insight in each step of the process the school feedback is based on. This way, the commercial aspect mentioned before is linked to a scientific one. Though there clearly is a commercial side to the school feedback project - it has something to offer that is for sale - the visitor is assured that the feedback is sound and legitimate. As the project is supported by academics of different universities, one can expect the calculations applied to be scientifically based, that is: reliable and valid. Moreover, these calculations are made fully transparent by means of detailed explanations and illustrations. One can consult the key terms and statistical values the feedback is made of, examine how to determine a school's 'added value' in a correct and straightforward manner, have a look at technical reports on the construction and comparison of test scores, and retrieve information on who (academics as well as policy makers) is leading, advising and financing the project. Through these sorts of references to the scientific character of the (components of) school feedback, the website enacts its authorization as 'evidence'.

According to the website, the feedback SFS offers is more correct and straightforward (than other types of feedback on performances), quick (feedback is delivered within a few days after importing the test scores) and fully automatic. As listed in the next two sections - "Our offers and our prices" and "How to proceed?" - all one needs to get started is right at hand. The tests schools can choose from to measure learning performances (either standardized tests offered by the Flemish educational government or tests developed by the Centre for School Feedback in a preparatory project), are displayed (see Figure 10). Letters to ask necessary information to parents and pupils (e.g. information on background characteristics that should be uploaded in the SFS) can be downloaded from the website. In addition, detailed information on privacy laws is provided in the "What about privacy" section, together with a hyperlink to a declaration form for electronic data processing which is legally required. As such, school feedback is staged not only as scientifically legitimate, but as legally legitimate as well. Or, its authorization is not only granted by making reference to the scientific, but also to the juridical domain. Furthermore, the tab "Our offers and prices" leads to standard offers for primary and secondary schools, as well as accustomed offers for other training institutions and educational researchers. Exemplary feedback reports can be consulted here, too. Schools can sign in per grade, per learning area, and per testing time (e.g. for mathematics at the end of the first grade). When schools import new test results after a new order, the feedback system automatically checks for previously delivered data, and, if present, this information is also linked automatically. Only those pupils that effectively made the test are charged on the school's account and once a school participates in three or more testing times with the same group of pupils, it receives two feedback reports for the price of one. Moreover, a discount is offered for all feedback orders till the end of June 2015 as was displayed in Figure 9. 


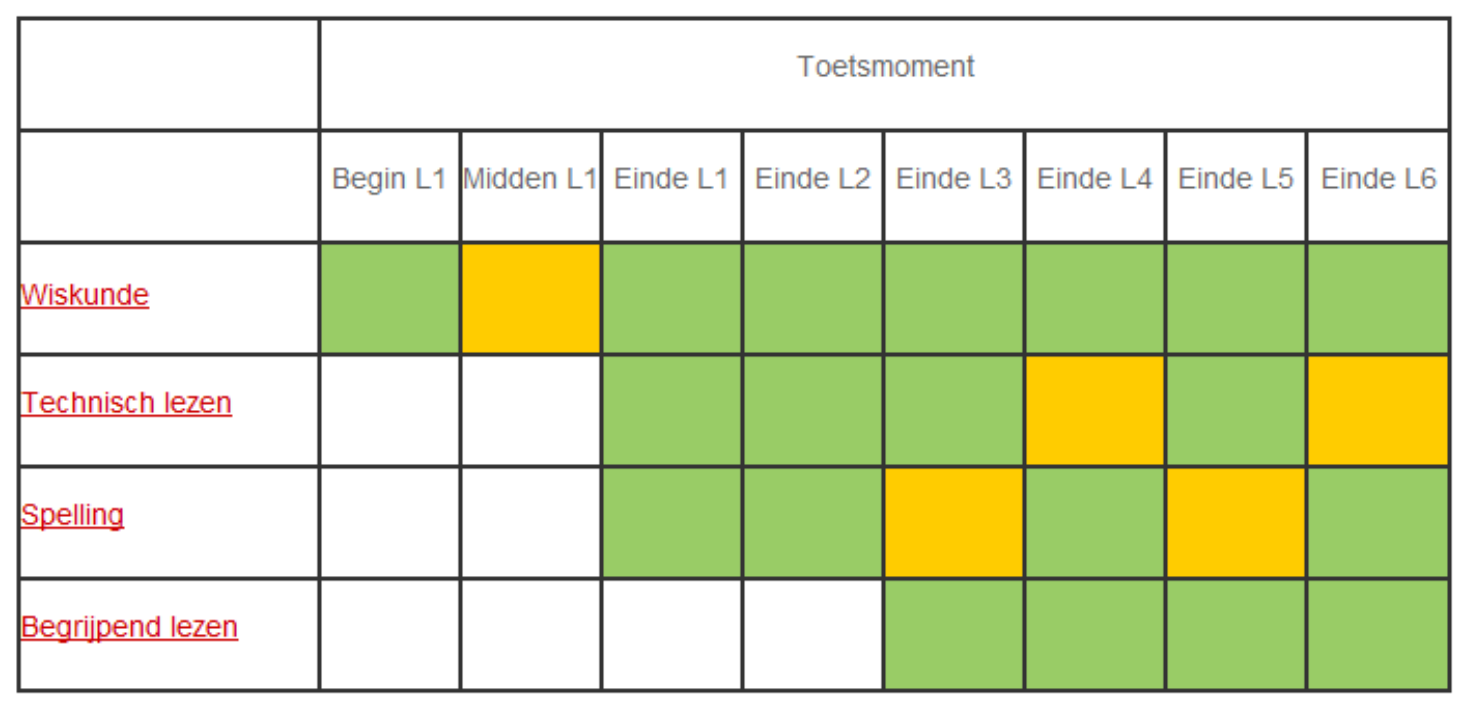

\section{Naar feedbackvormen}

Figure 10. An overview of the learning areas and testing times for which school feedback is available for primary education. Green areas are testing times on which feedback can be ordered, the yellow areas are those for which no additional feedback is available. Clicking on the learning domains leads to a screen where more detailed information on each of the tests in its various available versions can be downloaded.

This way, the school feedback website gives incentives to actually apply for and make use of the specific type of feedback provided by the SFS. In so doing, it stages its visitors as eager to know more about themselves, as well as eager to improve their own performances. To schools and educational institutions, it offers tests to make well-informed quality improvements; to researchers, it offers a sound system for data gathering and analysis. At once, what is to be seen in the SFS-mirror is staged as evidence. More precise: it stages feedback-as-evidence. If one really wants to know about school performances, the website conveys the message that this feedback is exactly what you need. That is, the school feedback website distinguishes between scientifically based - and thus 'real' - knowledge and non-scientific types of information on school performance. Promoting an interest in knowing is not the only thing the website does, though. Acquiring self-knowledge is to be seen as an investment: it is what is needed to optimize one's product (education). That is, the evidence SFS supplies ought to be turned to good account. As articulated on the "How to proceed?"-page, the fifth and last step in the process is to "pick up the feedback and...get started with it". A link leading to a chapter of an academic handbook (see Figure 11) relates the information provided by the feedback reports to the theory of 'policy capacity'. It suggests school teams to investigate why the results are what they are, which circumstances and characteristics of the school possibly may have led to these results, and how the school could improve these. Again, by making these links, information is staged as (scientific) evidence. 


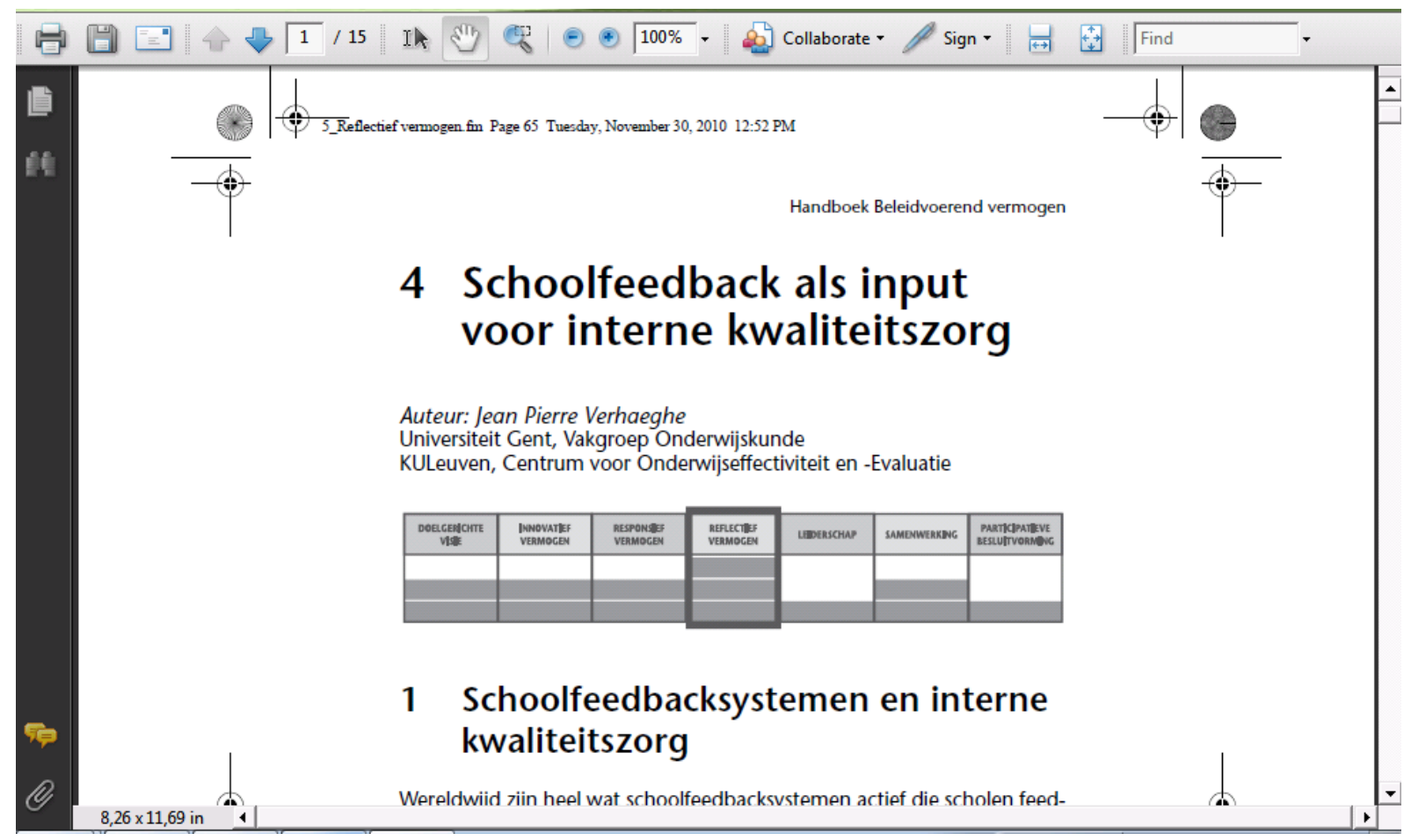

Figure 11. School feedback as input for internal quality assurance

Moreover, the tab "What about privacy?" stages the information the school feedback reports hold to be confidential and voluntarily. Indeed, the school feedback mirror is for internal use only. Precisely since it is essential for this mirror to be correct and not polished, it has to be cleared from the assessment of, and the competition between, schools. What schools get to see when looking in the SFS-mirror, therefore, is not to be used for reasons of accountability or publicity. What it is to be used for, though, is evaluation and improvement of the school's quality, that is, of quality immediately rephrased as 'adding value' through increasing the learning profit of its pupils. In other words, what school feedback makes you do - "you", the school; "you", the teacher; "you", the researcher - is to relate the work done in the school to the work done by an automatic school feedback system, and, in so doing, inscribing a calculative and profitable way of looking at one's own school.

\section{Discussion and conclusion}

By approaching each website as a socio-technical device, we sought to make explicit how specific operations performed on and by each website elevate information to the status of evidence. Each website performs technical operations that make schools appear as particular entities and also performs social operations that constitute a specific field of possible (inter)actions and meanings. By drawing on the descriptions of stagings and enactments in the previous sections, we will now discuss in more detail these technical and social operations performed through each website: the forms of inscription used, the spaces of equivalence that are opened up, the sort of sense making that is enabled, the type of authority that is installed and finally, the space of action that takes shape in front of the users of each website (see Table 2). 


\begin{tabular}{|c|c|c|c|}
\hline & Testing Grounds & Inspectorate & School feedback \\
\hline Form of inscriptions & $\begin{array}{l}\text { Stories/formatted } \\
\text { narratives }\end{array}$ & $\begin{array}{l}\text { Audit } \\
\text { reports/professional } \\
\text { judgments }\end{array}$ & $\begin{array}{l}\text { Numbers/school } \\
\text { performance }\end{array}$ \\
\hline Space of equivalence & $\begin{array}{l}\text { Space of (formatted) } \\
\text { narration }\end{array}$ & $\begin{array}{l}\text { Space of (standardized) } \\
\text { judgment }\end{array}$ & $\begin{array}{l}\text { Space of } \\
\text { (performance) } \\
\text { measurement }\end{array}$ \\
\hline Sense making through & Exemplification & Normalisation & Comparison \\
\hline Type of authority & Recognizability & Professionality & Accuracy \\
\hline Space of action & $\begin{array}{l}\text { Learning from } \\
\text { examples/experiences } \\
\text { in view of innovation }\end{array}$ & $\begin{array}{l}\text { Discrete consultation in } \\
\text { view of school choice }\end{array}$ & $\begin{array}{l}\text { Comparative self- } \\
\text { knowledge in view of } \\
\text { production of added } \\
\text { value }\end{array}$ \\
\hline
\end{tabular}

Table 2. The different operations performed through each socio-technical device.

Each website makes use of techniques of inscription (the process by which reality is transformed into figures, diagrams, texts - Latour, 1987; 1999) that constitute a particular space of equivalence for things of the world to become real, that is, for schools to turn into particular entities that start to make sense and that can be acted upon in different ways (cf. Desrosières, 1998). On the website of the inspectorate, for instance, a school is inscribed as 'audit report' in which qualitative, professional judgments according to the indicators of a standardized CIPO-frame make the particularities of each school appear. Each school thus 'appears' by means of, and becomes 'real' in, the formal, written accounts of professional judgments. On the school feedback website, a school is inscribed as 'numbers' in the form of feedback reports which contain comparative information regarding previous performance levels or the relative position vis-à-vis other schools. Through tables and numbers, schools are turned into particular realities. On the testing grounds website, schools are inscribed as 'stories about gardens' which have unique properties but which equally fit predetermined formats. Structured and formatted narratives function as inscriptions that give access to what a school is and does. Thus, each website portrays a school or a school practice as a distinct given through specific inscriptions, or, in other words: qualitative written judgments, tables and numbers or formatted narratives operate as inscription techniques through which the website achieves or enacts a school as a given reality or entity.

Each of the specific formats of inscription is furthermore staging schools-as-entities into common spaces in which these entities are rendered equivalent according to some aspects. Within these spaces of equivalence, particular forms of sense making and acting upon the evidenced schools are rendered possible. The SF-website installs a space where each school is measured in terms of its performance, and it is the comparison of these performances (i.e., comparison with one's own previous performance or with the average performance of comparable schools) that gives meaning to what a school is. What this installed space of measurement allows for, is an act of comparison of performance levels, or of levels of added value. Hence this particular space of equivalence produces meaning through comparison. In the case of testing grounds, appearing as a unique example assumes a space of pre-formatted narration. On the TG-website, then, sense making happens not through activities of comparison, but through acts of exemplification. Each narrated school appears 
as an example here, an example of for instance predefined categories (e.g. 'learning and choosing'), or of a disposition towards testing. An audited school, finally, appears as part of a space of judgment, that is, the application of professional criteria by the inspectorate, along the indicators of a standardized framework of context, input, process and output makes a school real. The predominant act of sense making as far as this website is concerned can be called normalization: the report of a particular audited school only becomes meaningful when, and in as far as, the space of judgment is accepted by the visitors of the website. Likewise, a school can (only) be known in terms of being more or less in accordance with norms or standards set. This way, each of the three websites creates a common space in which schools appear as having particular characteristics (being an example of, having an added value, having a normalized value) and hence making all those entities termed 'schools' interchangeable or equivalent regarding those particular characteristics (Desrosières, 1998; Stengers, 2005). Comparison, normalization and exemplification are hence not to be approached as merely mental activities (operated on predefined or pre-existing school practices), but are precisely enacted as part of very specific material and discursive inscriptions. Furthermore, as far as one is engaged in acts of comparison, normalization or exemplification, the space of measurement, judgment and narration is at once both assumed and reinforced.

Such highly specific worlds of sense making also enable discussions amongst different interested parties: discussions on the accuracy of measures, on the professionalism of inspectors, or on the richness of stories and examples. As far as the discussions are framed in these terms, and hence result potentially in increased accuracy, more professionalism and richer descriptions, each particular evidence-based assemblage is reinforced. This reinforcement articulates that each website, turning particular knowledge or information into evidence, at once installs a very particular kind of authority. An audit report on the inspectorate's website that turns into evidence at once stages the professional criteria used by the inspectorate: as reader of an audit report who considers this report as evidence concerning school quality, the criteria of the professional judgment of the inspectorate are being granted authority. On the SF-website, however, visitors considering and using feedback reports grant the objective measures authority as evidence. As far as the TG-website is concerned, visitors considering recognizable gardening stories as evidence that might assist in innovating one's school oneself grant authority to these very testing grounds (as producers of evidence). Whilst each website includes a process of authorization, this process largely differs in scope and is thus leading to different strategies of justification, that is, strategies to strengthen the 'evidence of evidence': authorization based on recognition (and the issue of the richness of each story), based on professionality (and the issue of discretion and trustful normativity of the report), based on accuracy (and issues related to reliability and validity of the feedback).

Thus far, we argued that all three websites - albeit three times in a different manner - give a statement about a given state of affairs ('evidence') by means of operations of inscription and the concomitant inauguration of particular spaces of equivalence, leading to different conceptualizations of the entity "school" and installing different types of authority. Equally and at the same time however, the stated evidence at once opens up a space of action that calls a specific kind of visitor into being. In other words: in the very act of producing this evidence and staging it on a website, very particular ways of dealing with schools is rendered possible. In the case of TG's, sharing experiences in the narrative form makes the act of learning from each other meaningful. This learning, furthermore, has a specific objective: to (start to) innovate. The space of action hence places the user of the website in a position where she has to think of herself as having to innovate and hence that 
one understands oneself and schools in terms of being capable to innovate. In the case of the inspectorate, discrete personal school choice (or any other private use) is what the website invites to. The space of action that the website of the inspectorate makes possible in this way, is a space of discrete consultation of the professionally judged quality of the school. The school, in other words, thus does not appear as a unique story to learn from here, but rather as the correlate of a contextualized, standardized judgment to enable or assure one's choice. Finally, in the case of SF, the space of action opened up is a space where self-knowledge on one's performance or monitoring becomes of crucial importance in view of the production of added value. But spaces of action - that is, what each website allows to do - also correlate with the very specific distribution of responsibilities or commitments - what each website urges its visitors to do: to learn and innovate, to consult discretely and to monitor added value.

In conclusion, some words on what this specific approach to websites as devices 'shows' and some final remarks on the effects of the studied digital spaces of evidence in the governance of education. First, analyzing websites as devices doing particular things and performing particular operations, displays operations of inscription, their according space of equivalence, shows how one is urged to make sense of entities as 'schools' in very different ways, points to different kinds of installed authority and opens up highly particular spaces of action. Furthermore, it allows to see that different 'school realities' emerge, that is, the digital spaces of evidence actually make schools real, makes them exist as an object of thought and correlate of action. What this mapping hopefully helps to understand is the kind of 'ontological regionalism' at stake here, that is, that there are different modes for schools to exist (cf. Latour, 2012). We would like to connect two remarks to these observations.

First, the suggested regional ontologies should not result in advocacy for some sort of constructivism or relativism. Instead, the entities we start to call 'schools' based on visiting these websites are both constructed and real, yet they exist in different manners. Schools actually come into existence, and (epistemological) discussions on for instance the validity and value of measurements, precisely assume and reinforce their existence. For that reason, the objective of this study was not to render evidence on schools 'weaker' or less valuable, nor to cause doubts regarding the existence of the evidenced schools. Instead of unmasking or celebrating pluralism, the socio-technological approach has another critical or political aim. Displaying the socio-technical operations and showing different modes of existence hopefully opens up a space in order to put them side by side, that is, reassemble these practices and to re- or undo some of their operations: scrutinizing which operations are at work, how they work precisely but also how they act in a very different manner, gives opportunities to discuss the very constitution of these assemblages and transform them, in Latour's (2004) parlance, from matters of fact into matters of (public) concern. The staging of different modes of schools to exist and to become evidence is perhaps a good antidote to, or at least a first step in the struggle against, those regions with imperial ambitions which claim their evidence to speak for itself. This brings us to a second and final thought. The focus was on websites, and hence on digital assemblages in the making. This approach, of course, was not directed to the actual usage of websites, but rather to the kind of user that is staged, and hence promoted. One could argue for that reason that this analysis is, at least indirectly revealing the kind of 'regional subjectivity' that is required from the users of such websites in order for a school to exist or to become real. This argument could motivate further research on the relation, and possible tension or even contradiction, between possible required 'regional subjectivities' that each are partly digitally 
constituted. A further exploration of the subjectivities that play a constitutive role in the governing through the evidenced schools as it takes shape today, should also focus on the kind of 'digital literacy' that is required to confront, and hence, debate and even recompose what becomes real. It is the kind of literacy that is required for subjectivities to speak themselves, instead of only being spoken to by the evidence whose stagings have been black boxed.

\section{Note}

All figures are screenshots retreived from the three different websites in the period of OctoberNovember 2012.

Figures of the testing grounds section were retrieved from:

ond.vlaanderen.be/proeftuinen, ond.vlaanderen.be/proeftuinen/algemeen/default.htm, ond.vlaanderen.be/proeftuinen/projecten/proeftuinthemas.htm and ond.vlaanderen.be/proeftuinen/netwerking\%20en\%20vorming/infobrochure.pdf

Figures of the inspectorate section were retrieved from:

ond.vlaanderen.be/doorlichtingsverslagen,

ond.vlaanderen.be/doorlichtingsverslagen/vragen/default.htm and

ond.vlaanderen.be/doorlichtingsverslagen/lijst.asp?niveau $=\mathrm{BaO} \& \mathrm{p}=\mathrm{V}$

Figures of the school feedback section were retrieved from:

schoolfeedback.be, schoolfeedback.be/inhoud/toetsenBasisonderwijsInhoud.html and schoolfeedback.be/inhoud/bestanden/Verhaeghe_Politeia.pdf

\section{Notes on contributors}

Mathias Decuypere is a PhD researcher of the Flemish Research Foundation (FWO) and affiliated to the Laboratory for Education and Society (University of Leuven). In his research, he investigates how the daily functioning of the University in general and its inhabiting academics in particular is composed of both human and non-human actors, and this by means of a sociomaterial and ethnographic approach.

Carlijne Ceulemans is a PhD researcher at the University of Antwerp. She works in teacher education at the Institute for Information and Education Sciences. Her PhD research develops a sociotechnical perspective on professional standards for teachers.

Maarten Simons is professor of educational policy and theory at the Laboratory for Education and Society of the University of Leuven (Belgium). His principal interests are in educational policy, new mechanisms of power, and new global and European regimes of governing education and lifelong learning. Moreover, in his research he focuses explicitly on the challenges posed to education with a major interest in (re-)thinking the public role of schools and universities, and the particular public and pedagogical role of teachers and academics.

\section{References}

Berns, T. 2009. Gouverner sans gouverner. Une archéologie politique de la statistique. Paris : PUF.

Bridges, David, Paul Smeyers, and Richard Smith. 2008. Educational research and the practical judgement of policy makers. Journal of Philosophy of Education 42 (1): 5-14. 
Callon, Michel, Cécile Méadel, and Vololona Rabeharisoa. 2002. The economy of qualities. Economy and society 31 (2): 194-217.

Collins, Peter. 2010. The ethnographic self as resource? In The ethnographic self as resource, edited by Peter Collins and Anselma Gallinat, 228-245. New York/Oxford: Berghahn Books.

Davies, Philip. 1999. What is evidence-based education? British Journal of Educational Studies 47 (2): 108-121.

Davies, Charlotte. 2008. Reflexive ethnography ( $2^{\text {nd }}$ ed.). London/New York: Routledge.

Decuypere, Mathias, Maarten Simons, and Jan Masschelein. 2011. "Perform, Measure Accurately, Optimize': On the Constitution of (evidence-based) Education Policy." International Studies in Sociology of Education 21(2): 115-135.

Delvaux, Bernard, and Eric Mangez. 2008. Towards a sociology of the knowledge-policy relation. Retrieved from http://knowandpol.eu/IMG/pdf/literature sythesis final version english.pdf

Desrosières, Alain. 1998. The politics of large numbers: A history of statistical reasoning. Cambridge, MA and London: Harvard University Press.

Fenwick, Tara. 2010. (un)Doing standards in education with actor-network theory. Journal of Education Policy 25 (2): 117-133.

Fenwick, Tara, and Richard Edwards. 2010. Actor-network theory in education. Abingdon: Routledge.

Flemish Parliament 2011. Vraag om uitleg van mevrouw Irina De Knop tot de heer Pascal Smet, Vlaams minister van Onderwijs, Jeugd, Gelijke Kansen en Brussel, over het gebrek aan onderzoek van onderwijsmethodes. Accessed January 292013. http://www.vlaamsparlement.be/Proteus5/showVIVerslag.action?id=620697

Foucault, Michel. 1982. Le sujet et le pouvoir. In Dits et écrits IV 1980-1988, edited by Daniel Defert, François Ewald, and Jacques Lagrange. Paris: Gallimard.

Grek, Sotiria. 2009. Governing by numbers: the PISA 'effect' in Europe. Journal of Education Policy 24 (1): 23-37.

Grek, Sotiria, and Jenny Ozga. 2008. Governing by numbers? Shaping education through data. CES Briefing 44. Retrieved from http://www.ces.ed.ac.uk/PDF\%20Files/Brief044.pdf

Gorur, Radhika. 2010. ANT on the PISA trail: Following the statistical pursuit of certainty. Educational Philosophy and Theory 43(1): 76-93.

Hargreaves, David H. 2003. Education epidemic: Transforming secondary schoolsthrough innovation networks. London: DEMOS.

Higgins, Vaughan, and Wendy Larner, eds. 2010. Calculating the Social. Standards and the Reconfiguration of Governing. Hampshire and New York: Palgrave Macmillan 
Lange, Bettina, and Nafsika Alexiadou. 2010. Policy learning and governance of education policy in the EU. Journal of Education Policy 25 (4): 443-463.

Lascoumes, Pierre, and P. Le Gales. 2007. Understanding public policy through its instruments. Governance 20 (1): 1-20.

Latour, Bruno. 1987. Science in action. Cambridge, MA: Harvard University Press.

Latour, Bruno. 1999. Pandora's hope: Essays on the reality of science studies. Cambridge, MA: Harvard University Press.

Latour, Bruno. 2004. Has critique run out of steam? From matters of fact to matters of concern. Critical Inquiry 30 (2): 225-248.

Latour, Bruno. 2005. Reassembling the social. An introduction to actor-network-theory. Cambridge, MA: Oxford University Press.

Latour, Bruno. 2012. Enquêtes sur les modes d'existence. Une anthropologie des modernes. Paris : La Découverte.

Law, John. 2009. Actor network theory and material semiotics. In The new Blackwell companion to social theory, edited by Bryan Turner, 141-58. Oxford, UK: Wiley-Blackwell Publishing.

Lawn, Martin. 2006. Soft governance and the learning space of Europe. Comparative European Politics 4: 272-288.

Nimmo, Richie. 2011. Actor-network theory and methodology: social research in a more-than-human world. Methodological Innovations Online 6 (3): 108-119.

Rose, Nikolas. 1991. Governing by Numbers: Figuring out democracy. Accounting, Organizations and Society 16 (7): 673-692.

Rose, Nikolas. 1999. Powers of freedom. Reframing political thought, Cambridge: Cambridge University Press.

Savage, Mike, Evelyne Ruppert, and John Law. 2010. Digital devices: Nine theses. CRESC Working paper series No. 86.

Simons, Maarten. 2007. "'To be Informed': Understanding the Role of Feedback Information for Flemish/European Policy." Journal of Education Policy 22(5): 531-548.

Slavin, Robert. 2002. Evidence-based education policies: Transforming educational practice and research. Educational Researcher 31 (7): 15-21.

Smet, Pascal. 2009. Beleidsnota onderwijs 2009-2014. Samen grenzen verleggen voor elk talent. http://www.ond.vlaanderen.be/beleid/nota/2009-2014.pdf 
Stengers, Isabelle. 2005. The cosmopolitical proposal. In Making things public: Atmospheres of democracy, edited by Bruno Latour and Peter Weibel, 994-1003. Cambridge, MA: MIT Press.

Venturini, Tommaso. 2012. "Building on Faults: How to Represent Controversies with Digital Methods." Public Understanding of Science 21(7): 796-812.

Verckens, Anneleen, Maarten Simons, and Geert Kelchtermans. 2009. "Welke overheid voor welk onderwijs [Which Government for which Education]?” Pedagogische Studiën 86(1): 21-40. 